\title{
Reconstruction of finger joints using autologous rib perichondrium - an observational study at a single Centre with a median follow-up of 37 years
}

Daniel Muder ${ }^{1,2}$, Ola Nilsson ${ }^{3,4}$ and Torbjörn Vedung ${ }^{1,5^{*}}$ (D)

\begin{abstract}
Background: Gratifying long-term results are difficult to achieve when reconstructing osteoarthritic finger joints. Implant surgery is the most commonly used method to restore function and dexterity. However, all types of implant have disadvantages and may be a less favorable option in some cases, especially in young patients with a long expected lifetime and high demands on manual load. Implant related complications as loosening, instability, subsidence and stiffness are the main concerns. In this context, joint reconstruction using rib perichondrium might be a reasonable alternative in selected cases. The aim of the study was to evaluate the long-term results of finger joint reconstruction using rib perichondrial transplantation.
\end{abstract}

Methods: The study group $(n=11)$ consisted of eight individuals reconstructed in the proximal interphalangeal (PIP) joints and three reconstructed in the metacarpophalangeal (MCP) joints during 1974-1981. All patients were evaluated at clinical visits (median: 37 years after perichondrial transplantation, range: 34-41 years) using radiographs, disability in arm-shoulder-hand (DASH) score, Visual Analog Scale (VAS), range-of-motion (ROM) and manual strength (JAMAR).

Results: None of the 11 patients had undergone additional surgery. All of the PIP-joints $(n=8)$ were almost painfree at activity (VAS 0,6) (range 0-4), had an average range-of-motion of 41 degrees (range 5-80) and a mean DASH-score of 8,3 (range 1-51). The mean strength was $41 \mathrm{~kg}$ compared to $44 \mathrm{~kg}$ in the contralateral hand (93\%). The three MCP joints were almost pain-free at activity (VAS 0,7), (range 0-1). The ROM was on average 80 degrees (range 70-90) and the mean DASH-score was 2 (range 1-3). The mean strength was $43 \mathrm{~kg}$ compared to $53 \mathrm{~kg}$ in the contralateral hand (81\%).

Conclusions: Perichondrium transplants restored injured PIP and MCP joints that remained essentially pain-free and mostly well-functioning without need for additional surgeries up to 41 years after the procedure. Additional studies are needed to evaluate long-term results in comparison to modern implants and to better describe the factors that determine the outcome of these procedures.

(Continued on next page)

\footnotetext{
*Correspondence: torbjorn.vedung@surgsci.uu.se

'Department of Surgical Sciences/Orthopedics \& Hand Surgery, Uppsala

University Hospital, Entrence 701 floor, 75185 Uppsala, Sweden

${ }^{5}$ Elisabeth Hospital Aleris, Geijersgatan 20, 75226 Uppsala, Sweden

Full list of author information is available at the end of the article
}

(c) The Author(s). 2020 Open Access This article is licensed under a Creative Commons Attribution 4.0 International License, which permits use, sharing, adaptation, distribution and reproduction in any medium or format, as long as you give appropriate credit to the original author(s) and the source, provide a link to the Creative Commons licence, and indicate if changes were made. The images or other third party material in this article are included in the article's Creative Commons licence, unless indicated otherwise in a credit line to the material. If material is not included in the article's Creative Commons licence and your intended use is not permitted by statutory regulation or exceeds the permitted use, you will need to obtain permission directly from the copyright holder. To view a copy of this licence, visit http://creativecommons.org/licenses/by/4.0/. The Creative Commons Public Domain Dedication waiver (http://creativecommons.org/publicdomain/zero/1.0/) applies to the data made available in this article, unless otherwise stated in a credit line to the data. 
(Continued from previous page)

Level of evidence: Level IV, Therapeutic Study.

Keywords: Articular cartilage, Perichondrium, Transplantation, Joint reconstruction

\section{Background}

A variety of methods aiming towards cartilage repair or regeneration have been developed and tested over the years $[1,2]$. Early attempts to transplant autologous cartilage for reconstructive purposes to the ear, nose or joints failed. Some of the early investigations used autologous costal cartilage that was diced, sliced or molded into a usable structure, and then transplanted [3]. However, these experimental models did not produce new cartilage or were not applicable clinically. Eventually, pieces of cartilage were successfully transplanted into small articular cartilage defects and this strategy has been further developed and is now standard clinical practice, especially for traumatic injuries in athletes [46]. In addition, autologous chondrocyte transplantation is used at some centres $[4,7,8]$, but this technique is not useful in small joints when the entire joint surface must be restored. Finding alternative methods required suitable tissues to transplant as well as solving the problem with attachment of the graft to the recipient site. In this context rib perichondrium was found to be a suitable tissue [9].

The perichondrium is a layer of dense connective tissue that surrounds the cartilage of the developing skeleton. It also surrounds non-skeletal cartilaginous tissues including the tip of the nose and the helix of the ear [10]. It consists of two separate layers: an outer fibrous layer important for mechanical and structural support and an inner cambium layer containing osteochondroprogenitor cells [11]. Perichondrial cells are known to play a role in regulating chondrocyte differentiation and respond to signals from underlying chondrocytes [1214]. For example, in the cartilaginous bone templates of long bones, chondrocytes undergo proliferation, column formation and hypertrophy resulting in longitudinal bone growth. Simultaneously, flanking perichondrium differentiates into periosteum and serves as a source for both trabecular and cortical osteoblasts [15-17]. Early clinical observations suggested and experimental studies supported that perichondrium also has chondrogenic potential [18-20]. This chondrogenic potential of perichondrium and its potential for regeneration of articular cartilage was further investigated in the 1970s [3, 9] and has since then been used at our centre to reconstruct articular surfaces in small joints damaged by infection and/or trauma [21, 22]. It was a relatively widespread surgical technique during the following decades [23-25]. However, starting in the early 90 s, partly due to variable results $[22,24]$ and partly due to improved implants, the usage of the technique declined. The need of a second surgical site may also in part explain the limited use of this method [26]. The aim of the present study was to evaluate the long-term outcome after all perichondrial transplantations to the proximal inter-phalangeal (PIP) joint and the metacarpophalangeal (MCP) joint of the hand performed at Uppsala University Hospital during 1974 to 1981.

\section{Methods \\ Retrospective chart review of perichondrial transplantations to the PIP and MCP joints}

In order to evaluate long-term clinical outcome of joint reconstruction by perichondrial transplantation, a retrospective chart review was performed and identified 14 living and locatable patients that had undergone autologous perichondrial transplantation to the PIP and MCP joints between 1974 and 1981 at Uppsala University Hospital. The timeframe starts with the primary case in 1974 and ends in 1981 when the journal system was altered. Twenty-six patients could not be included in the study due to the following reasons: 19 deceased, 7 not located. Hence, the loss to follow-up was $26 / 40$ (65\%). In addition, three of the PIP cases were excluded since they had been converted into fusion shortly after the primary surgery (range 3-25 months postoperatively) and had no joint to asses. The reason for these failures was persistent pain and stiffness. The remaining and final study group $(n=11)$ included 8 patients with reconstructed PIP joints and 3 patients with reconstructed MCP joints. They were contacted by letter and all responded and agreed to participate in the study by written informed consent.

The patients were assessed with plain radiographs and by measuring range-of-motion (ROM) with goniometer. Manual strength was assessed by a JAMAR hand dynamometer (Patterson Medical Ltd., Nottinghamshire, UK). Pain was assessed with Visual Analog Scale (VAS), (scale: 0 (no pain) to 10 (most severe pain)). Manual ability was assessed with Quick DASH (The disabilities of the arm, shoulder and hand score), (scale: 0 (no disability) to 100 (most severe disability) [27]. All measurements and examinations were done by the same observer (DM).

In all cases but one the joint problem was caused by dislocation, intra-articular fracture and/or posttraumatic 


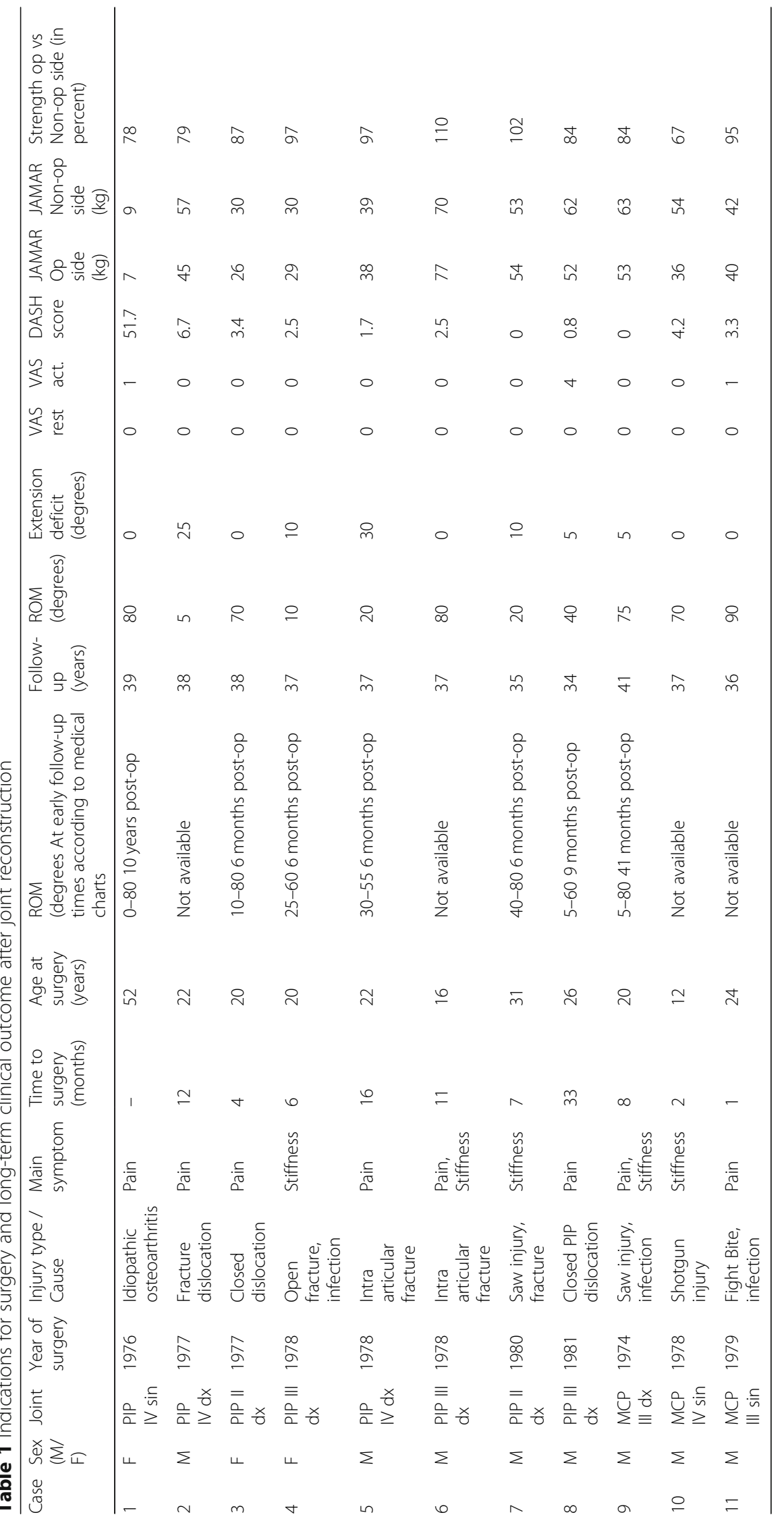


infection. The time from injury to surgery was on average about 10 months (range 1-33 months) (Tab. 1). Several of the subjects have been active in physically demanding occupations for many years after the surgery.

Some of the cases in the present cohort has been reported previously at early stages after the surgery including the first case from 1974. In the primary case preoperative radiographs revealed severe osteoarthritis with destruction of the articular cartilage (Fig. 1a; reproduced with permission of SAGE Publishing) [28]. Radiographs, 6 months postoperatively, showed a wider joint space compared to the preoperative findings and some slight irregularities in the subchondral bone (Fig. 1b; reproduced with permission of SAGE Publishing) [28]. An arthrography 3.5 years postoperatively indicated smooth and congruent joint surfaces (Fig. 2; reproduced with permission of SAGE Publishing) [28],

\section{Surgical technique}

Standardized surgical technique in brief, all remnants of the eroded joint surfaces (both sides of the joint) are resected down to bleeding subchondral cortex. Care is taken to preserve the shape of the joint surfaces. The perichondrium is harvested from the 6th or 7th rib. A skin incision is made in the sub-mammary crease, starting from the osteochondral junction (a slightly elevated rim in the mid-clavicular line) and stopped at the medial margin of the crease to avoid unsightly scarring. The rectus abdominis fascia and underlying muscle is divided transversely to expose the donor site. The perichondrium is incised along the superior and inferior borders of the cartilaginous part of the donor rib. A transverse incision is made in the rib periosteum a few millimetres lateral to the bone-cartilage rim. This small portion of periosteum is temporarily included in the graft to enable grasping and pulling. The perichondrium is lifted at the bone-cartilage rim of the rib and peeled off the underlying cartilage with a blunt dissector all the way to the sternum. The last centimetres of dissection from medial margin of the skin incision to the lateral margin of the sternum is done subcutaneously. Care is taken not to include any cartilage and not to damage the cambium (inner) layer of the perichondrium. The perichondrium is osteo-sutured at the joint margins of the recipient site with the cambium layer facing towards the joint space and the outer fibrous layer facing the subchondral bone. A thin silicone sheet is temporarily placed in the joint and helps mold the transplant and prevents adherence between the reconstructed joint surfaces. The hand is immobilized in a cast in "the position of safety" [29] for 4 weeks, followed by physiotherapy. The silicone membrane is subsequently removed in a second operation, after 4 months in the present study group. In the beginning of the 80 's the technique was slightly modified as fibrin glue was added to reinforce the attachment of the graft [30]. The cohort in the present study was operated before this modification.

\section{Statistical methods}

The difference in grip strength between operated and unoperated joint/hand were analyzed with paired t-tests and data were expressed as mean $\pm \mathrm{SD}$. All data were analysed using the SPSS software version 23 (IBM).

\section{Results}

\section{Clinical assessment}

All patients $(n=11)$ underwent clinical evaluations including assessment of pain, range-of-motion (ROM),

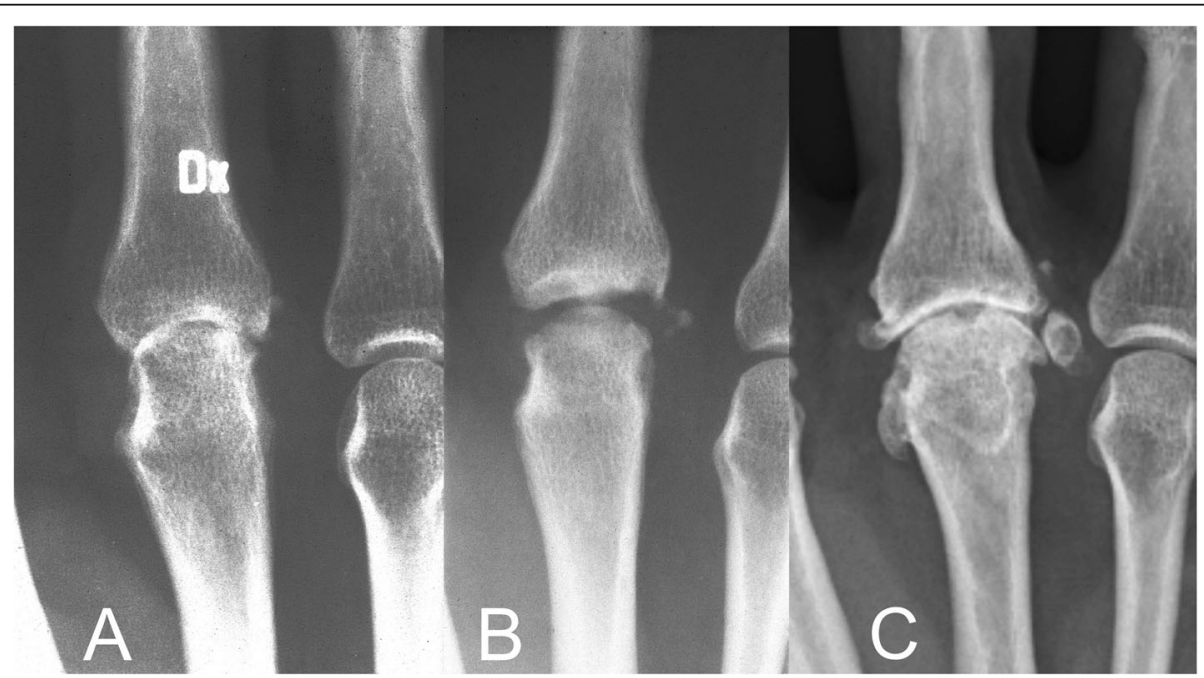

Fig. 1 Radiographs (AP view) of the third metacarpophalangeal joint in the primary case from 1974 (case 9) before (a), 6 months after (b), and 40 years after (c) perichondrial reconstruction of the joint. Reproduced with permission of SAGE Publishing [28] 


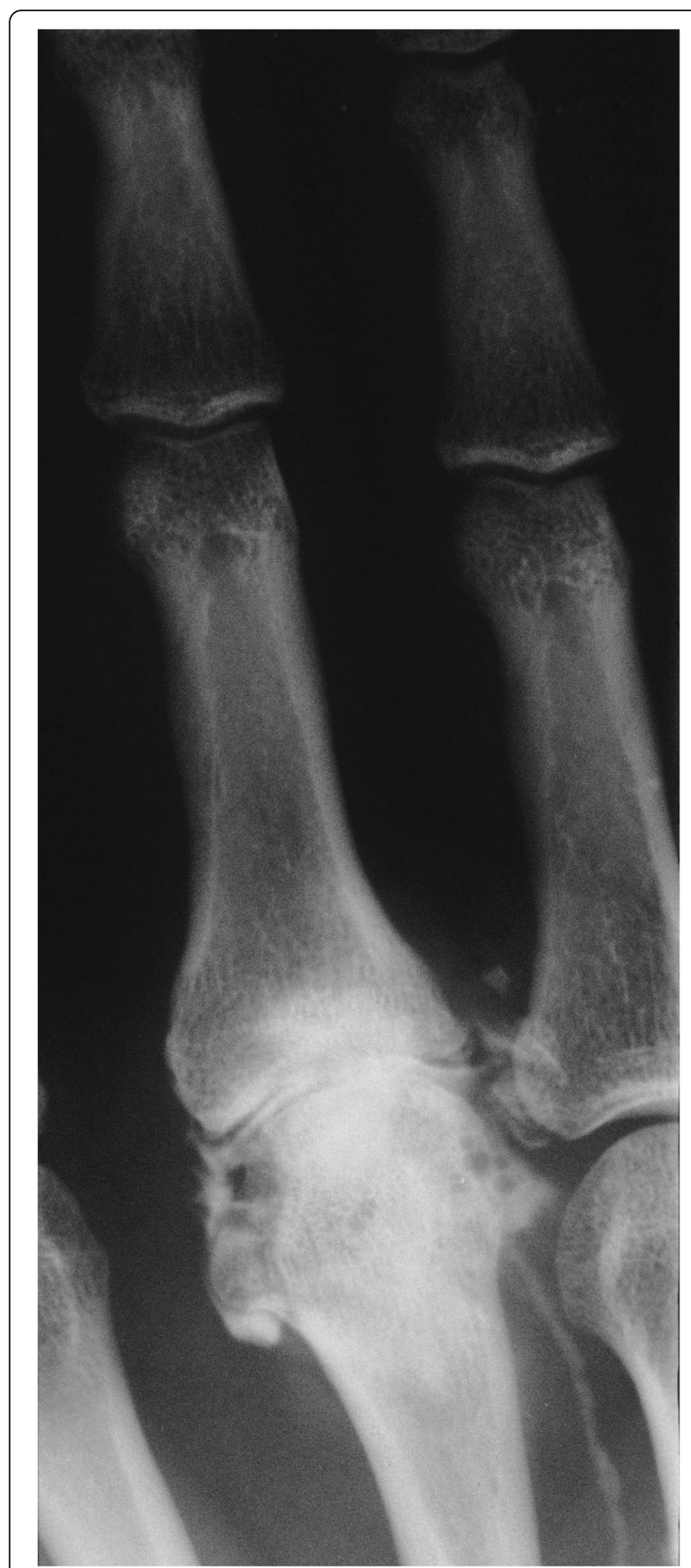

Fig. 2 Arthrography 3.5 years postoperatively, revealing some periarticular irregularities but a smooth joint space with even surfaces. Some contrast is also seen proximally in an inter-metacarpal lymph vessel. Reproduced with permission of SAGE Publishing [28]

and function (DASH) on average 37 years (range 34-41 years) after the original procedure. None of the 11 patients had received additional surgical treatment of the reconstructed joints. The eight PIP joints were pain-free at rest (average VAS $0 ;$ Tab. 1) and almost pain-free during activity (average VAS 0.6: range 0-4; Tab. 1). The total range-of motion (ROM) was on average 41 degrees (range 5-80 degrees; Tab. 1). Three of the PIP joints had nearly full ROM (70-80 degrees). In three PIP joints the ROM were 20-40 degrees, which was less than optimal but still allowed for a reasonable function in the affected fingers. The remaining two PIP joints had poor ROM (only 5-10 degrees). The mean DASH-score was 8.7 (range $0-51$; Tab. 1). The DASH score was 6.7 or lower in all cases but one. The high DASH-score in case 1 is probably influenced by other problems as indicated by the impaired manual strength on both sides and the age of the subject (91 years). Average hand strength was similar in the operated hand compared to the contralateral hand ( $41 \mathrm{~kg} \pm 21$ vs. $44 \mathrm{~kg} \pm 20 ; P=0.24$; Tab. 1 ). The mean extension deficit was 10 degrees (range $0-30$ ).

The three MCP joints were pain-free both at rest (average VAS 0) and during activity (average VAS 0; Tab. 1). Five degrees' extension deficit was found in one out of three cases, but the total ROM was essentially normal in all three patients (average 78 degrees; range 70-90) (Fig. 3). The mean DASH-score was 2.5 (range $1-3)$. The mean strength was similar in the operated hand compared to the contralateral hand ( $43 \mathrm{~kg} \pm 8.9$ vs. $53 \mathrm{~kg} \pm 10.5 ; P=0,16$; Tab. 1 ).

None of the patients had any donor site morbidity or complaints. The resulting scars were effectively hidden in the sub-mammary crease in all available patients $(n=11)$.

\section{Radiological assessment}

Radiographs of the primary case obtained before (Fig. 1a) and 6 months after the procedure (Fig. 1b) indicate that a wider joint space is regained after the surgery. Arthrography 3.5 years postoperatively, suggested smooth joint space with even surfaces and only minor irregularities. However, at long time follow-up (average follow-up time 37 years) radiographs in several cases showed significant signs of osteoarthritis including subchondral sclerosis, cysts, loose bodies and osteophytes at the joint margins (Fig. 1c, Fig. 4, Fig. 5). Interestingly, radiographic osteoarthritis did not correlate with clinical signs of osteoarthritis. This discrepancy between clinical impression and radiological appearance has also been reported at short term follow-up studies $[26,28]$.

\section{Discussion}

The main goal of the present study was to assess longterm outcome after perichondrial transplantation to the PIP and MCP joints of the hand. We found that none of the 11 cases in the study cohort had required any second surgery, that all remained reasonably well functioning and pain-free at rest, and that all patients but one, were essentially pain-free during exercise and strain (Tab. 1). 


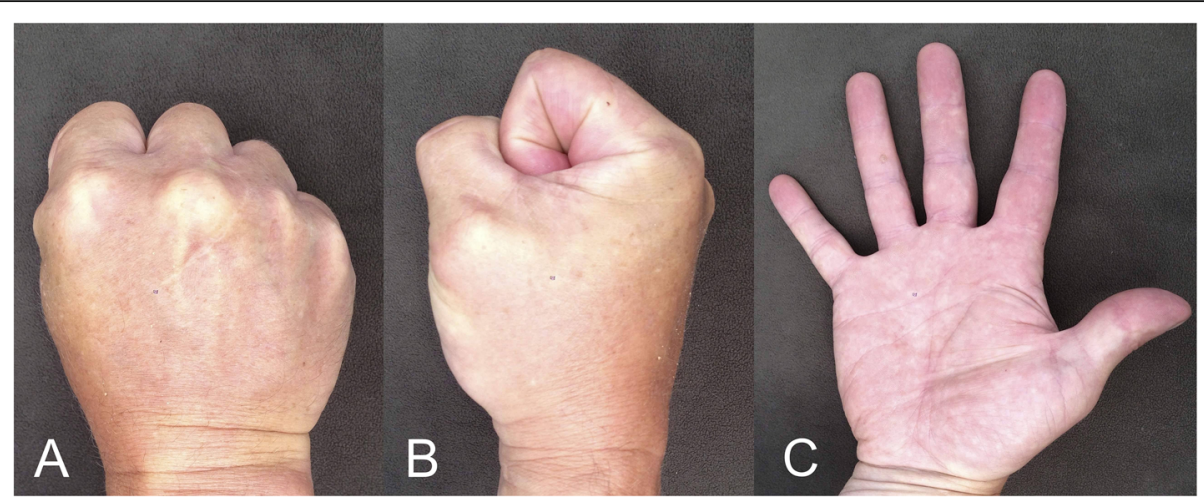

Fig. 3 The range-of-motion in the reconstructed third metacarpophalangeal joint in the primary case from 1974, 40 years after the surgery: a, Flexion (dorsal view); b, flexion (lateral view); c, extension (volar view)

Perichondrial transplantation has been applied to a variety of joints; e.g. different joints in the hand, the wrist, the elbow, the knee, and the foot [22, 23, 25, 31]. Minor modifications of the original surgical technique and the postoperative regime was introduced in the 80's; in addition to osteo-suture, attachment of the graft is often reinforced with fibrin glue [30], and extraction of the silicone membrane is nowadays normally done after 6-8 weeks [26].

However, there are few long-term outcome reports in the literature. In 1980, Engkvist et al. reported shortterm results (range 3-41 months) of twenty-six perichondrial transplantations [22]. The surgical indication varied considerable in the study group, e.g. congenital malformations, rheumatoid arthritis, degenerative osteoarthritis, and post-traumatic osteoarthritis that in some cases were associated with significant soft tissue trauma. The operated joint also varied significantly; eleven MCP joints, eight PIP joints, four trapezio-metacarpal joints, two metatarsophalangeal joints of the big toe and one elbow. The interpretation of the results in such variable cohort becomes difficult and the outcome was, as could be expected, variable but in some cases, excellent [22]. Seradge et al. reported a retrospective study of thirty-six perichondrial transplantation with a minimum follow-up of three-years [24]. This study group was more homogenous with sixteen MCP joints and twenty PIP joints. The results graded as good (no pain, absent or occasional swelling, and useful ROM) were comparable in the MCP (56\%) and the PIP joints (55\%). They concluded that the outcome was better in younger patients and suggested that the method should be avoided in patients older than 40 years of age. Although there was a tendency towards better results in teenagers and young adults, this conclusion seems to be based on very few observations. Only two patients older than 40 years of age were available for age evaluation (one MCP and one PIP joint) and both were graded as fair (useful ROM with or without minimal swelling and occasional discomfort) [24] and the negative effect of increasing age may thus be over-stated in this study.

In our series, only one patient was older than 40 years (52 years) at the time of surgery (Tab. 1, case 1 ). However, in this patient the reconstructed PIP joint had excellent ROM (80 degrees) with minimal pain (VAS 1) at activity 39 years later, demonstrating that favourable long-term out-comes is possible beyond young adulthood.

The discrepancy between the clinical impression and the radiological appearance is interesting. The irregularities were mostly seen in the joint margins as osteophytes (Fig. 4-5). The joint space in the reconstructed joints was in general narrower than in the neighbouring normal joints but the joint surfaces seem to be smooth. Resorption and remodelling of the cortical bone contour have been reported to occur after perichondrial transplantation $[26,28]$, and similar finding were found in the present study.

The total ROM in the primary case from 1974 was 75 degrees (range 5/80) 41 months after the surgery [22], which is similar to our findings during the 40-year follow-up evaluation (Tab. 1, case 9, Fig. 3). The relative grip strength in the operated and un-operated (dominant) hand has remained similar over time, 95\% (95/100 $\mathrm{kg})$ in the 41-months follow-up and $84 \%$ in the 40 -year follow-up $(53 / 63 \mathrm{~kg})$. The reduction in strength is similar to the decline in strength that occurs with age in the general population [32]. The ROM at various early follow-up times in seven of the cases are displayed in Table 1. In five of the cases (case 1,3,5,8-9) the shortterm results are almost identical to the long-term results obtained several decades later (Tab. 1). In the 70's, available implants consisted mainly of silicone prostheses [33]. However, even if a modern non-constrained implant may have restored the function equally well, it would probably not have lasted for 35-40 years without 

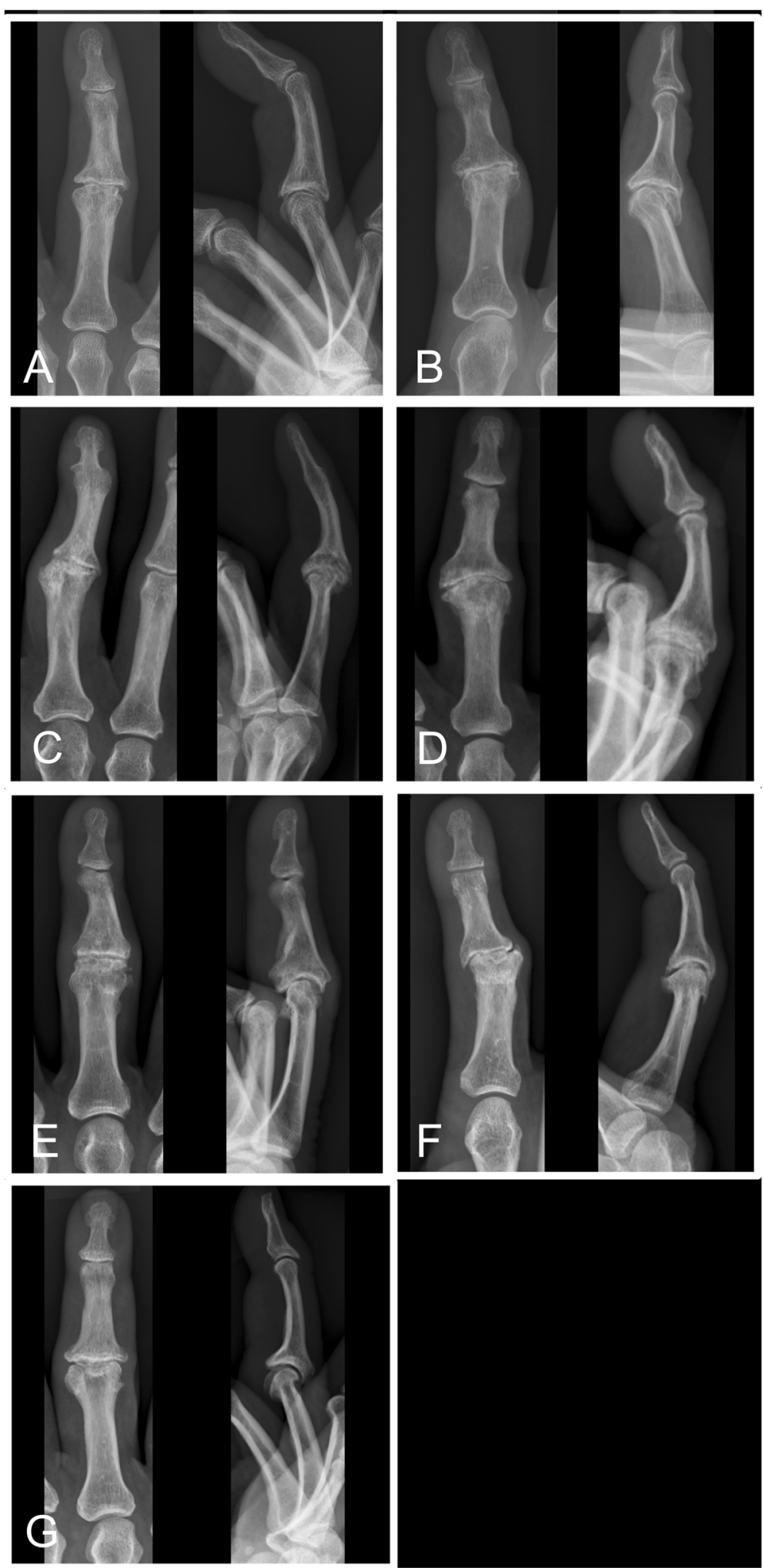

Fig. 4 Radiographs of the reconstructed proximal interphalangeal joints in case 2-8 (a-g). No radiographs were obtained in case 1 before the patient passed away 


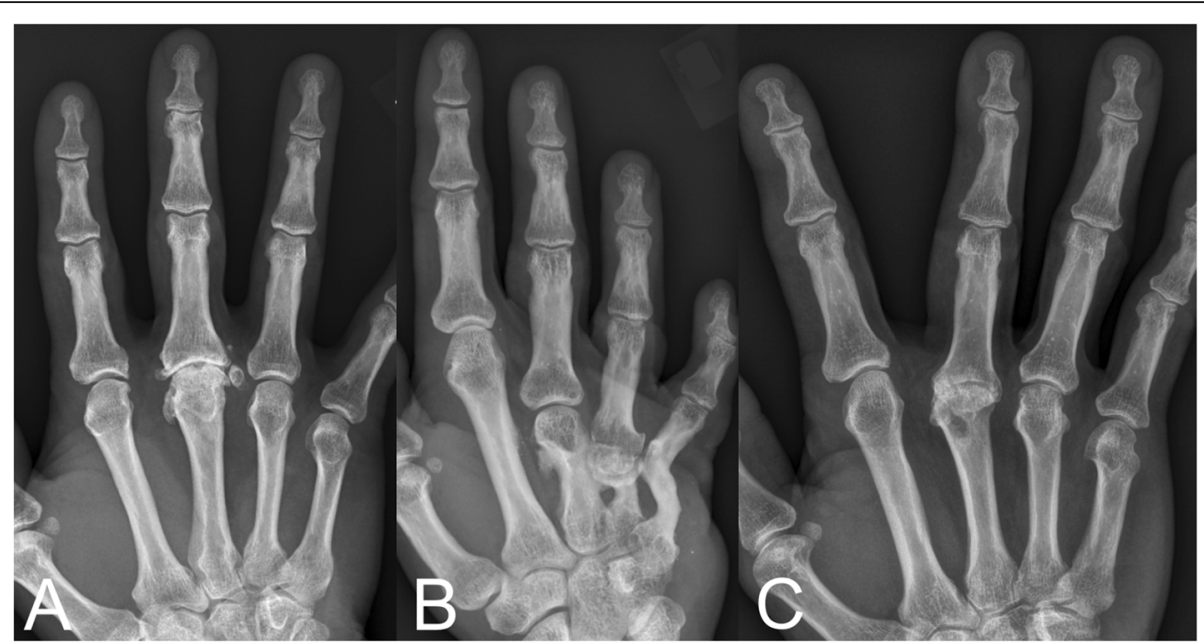

Fig. 5 Radiographs of the reconstructed metacarpophalangeal joints in case 9-11 (a-c). The joint space in case 10 (MCP IV) was difficult to visualize due to the bony deformities caused by the shotgun injury in 1978

the need for a re-surgery. In addition, revision surgery after a failed implant is difficult due to the altered anatomy. In contrast, with the perichondrial transplantation technique, the option for later implant arthroplasty is preserved since most of the bone and soft tissues around the joint is left intact. Additional studies are required to develop and evaluate the current method. New experimental techniques and approaches including cell-tracing technologies have opened new possibilities to study skeletal development, growth, and regeneration [34] and may thus be helpful to evaluate the cellular origin and mechanisms important for the outcome of the current surgical method.

The extensive observation period is both a strength and a weakness. It enables a rare opportunity to asses clinical outcome several decades after the surgery. It is also coupled with an inevitable and large loss to clinical follow-up. All patients who fulfilled the inclusion criteria; perichondrium transplantation to the PIP or MCP joints, being locatable and alive, responded and agreed to participate in the study. Three of the PIP joints identified in the retrospective chart review had been converted to fusion shortly after the primary surgery and were excluded in the present study, as they had no joint to assess. However they are important to display and consider. The postoperative complications that necessitated these fusions included persistent pain and stiffness, but the mechanistic reasons for these failures could not be elucidated from the patient files. Potential causes may be poor transplant quality or detachment of grafts. In addition, this cohort of patients was the first to undergo perichondrial transplantation, a completely new method at the time. The number of cases in the present study is relatively small, especially in the MCP group, which limits interpretation of the results. There were only three
$\mathrm{MCP}$ cases and the positive results in this study may be reproducible in future studies with larger number of patients. Another possibility for the favourable results may be that articular cartilage in some cases was not completely destroyed. Remnants of native cartilage could potentially have contributed to the favourable outcomes. However, this is unlikely since the arthritic joint surfaces were almost completely devoid of articular cartilage before the procedure and then resected and completely covered with perichondrium during the procedure [21, 35]. Furthermore, due to the limited regenerative capability of articular cartilage, it is less likely that small pieces of cartilage remnants would have made major contributions to the resurfacing of the joint surface [21, 35 . We did not have a suitable control group and it is therefore not possible to determine if transplantation of other tissues, i.e. periosteum [36] or extensor retinaculum [37], would have produce similar results.

Non-constrained surface replacement implants, with a proximal and a distal component, have become increasingly more popular during the last decades. However, regardless of type, these implants struggle with complications such as loosening, subsidence, joint instability, joint contracture, swan neck deformity, malalignment, dislocation etc. [38]. Shortterm results may be gratifying but in the long-term complications often emerge (summarized in Tab. 2 [40, 42-48]). Silicone implant arthroplasty is still a widely used method to reconstruct destructed finger joints in the rheumatoid patient, especially at the MCP level [38]. However, silicone implants are a suboptimal alternative in the non-rheumatoid patients, especially in young individuals, since these implants are coupled with a high fracture rate [39, 41] (Tab. 2). In a long-term follow-up (14 y) of 52 


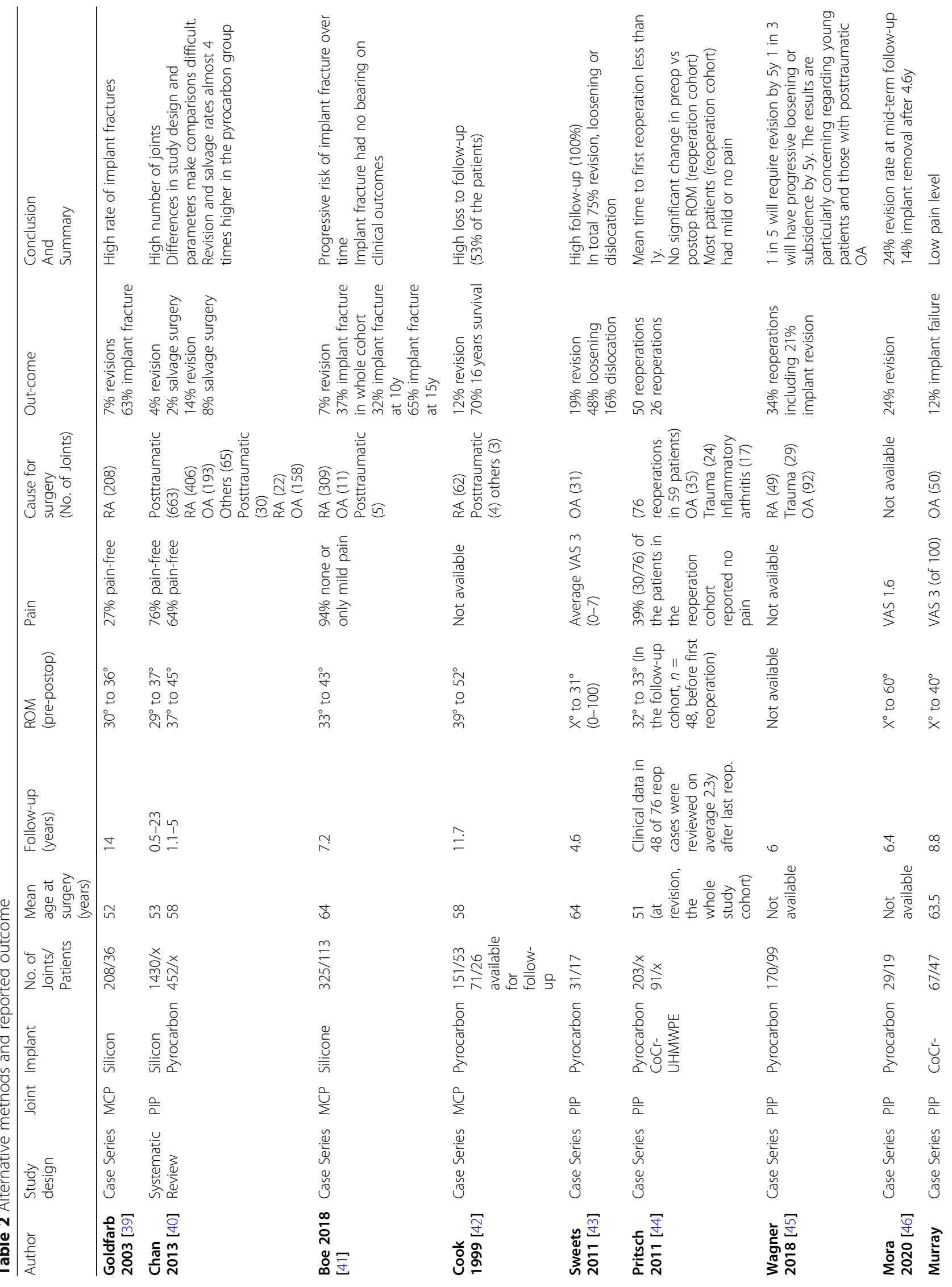




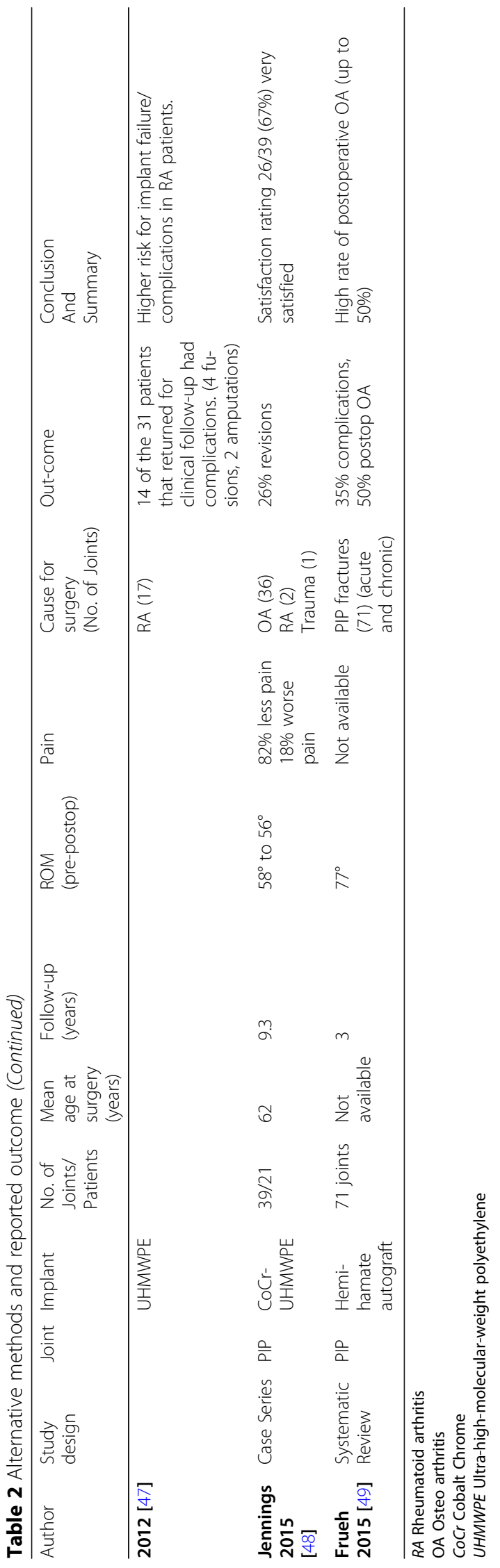


rheumatoid patients who underwent simultaneous silicone MCP joint arthroplasties of all four fingers, implant fracture rate was as high as 63\% (130/208 implants), and persistent pain ranging from occasional to constant was reported in up to $73 \%$ of the hands [39] (Tab. 2). A variety of other methods have been used to reconstruct and resurface eroded PIP and MCP joints, e.g. periosteum [36], extensor retinaculum [37] and corium (dermis graft) [50]. None of these autograft methods have been shown to be superior and they are not widely used at present. Autologous hemi-hamate autograft is another method to consider when the destructed joint surface is limited to the palmar lip of the middle phalanx after a dorsal fracture dislocation at PIP level. In a systematic review, this technically challenging method was reported to have an overall complication rate at around 35\% and a long-term osteoarthritis rate as high as 50\% [49] (Tab. 2).

The ultimate goal of an articular cartilage repair is to restore the native tissue structure but the outcome, regardless of the surgical method used, is generally believed to be fibro-cartilaginous at best [51]. The nature of the resulting tissue is scientifically interesting and important but the primary measure of success in a clinical perspective is to achieve long-term joint function and pain relief [52].

\section{Conclusions}

In summary, we found that resurfacing of injured finger joints using transplanted perichondrium can provide acceptable long-term results. In this context, the three early failures are important to consider. However, the remaining study cohort $(n=11)$ had no additional surgery to the reconstructed joint and was assessed after an average of 37 years. Our findings suggest that function of the resurfaced joints will remain favourable in the long-term in most patients with favourable short-term outcome. Further studies are needed to determine if this method can be developed into a method that is safe and efficacious. These studies should focus on factors that may improve short-term outcomes, evaluate the surgical method in comparison to modern implant surgery, and to clarify the mechanisms by which perichondrial transplants support the formation of functional joint surfaces.

\footnotetext{
Abbreviations

PIP: Proximal interphalangeal; MCP: Metacarpophalangeal; DASHscore: Disabilities of the arm, shoulder and hand score; n: Number; Kg: Kilogram; ROM: Range of motion; VAS: Visual analogue scale; IBM: International business machines corporation; Tab: Table; Fig: Fig.; RA: Rheumatoid arthritis; OA: Osteoarthritis; CoCr: Cobalt Chrome; UHMWPE: Ultra-high molecular-weight polyethylene
}

\section{Acknowledgements}

The authors wish to thank Professor Nils Hailer, department of Surgical Sciences Uppsala University, Uppsala Sweden, for fruitful collaboration and important input during the final stages of the study.

\section{Authors' contributions}

DM: Study design, data acquisition, statistical analysis and writing of the manuscript. ON: Study design, data interpretation and writing of the manuscript. TV: Study concept and design, data interpretation and writing of the manuscript. All authors have approved the final manuscript.

\section{Funding}

The work by TV and DM was supported by grants from the Uppsala County Council. The work by ON was supported by grants from the Swedish Research Council [project K2015-54X-22 736-01-4, 2015-02227]; the Swedish Governmental Agency for Innovation Systems (Vinnova) [201401438]; Marianne and Marcus Wallenberg Foundation; the Stockholm County Council; Byggmästare Olle Engkvist Stiftelse; the Swedish Society of Medicine; Novo nordisk Foundation; Erik och Edith Fernström Foundation for Medical Research; HKH Kronprinsessan Lovisas förening för barnasjukvård; Sällskapet Barnavård; Stiftelsen Frimurare Barnhuset i Stockholm; Nyckelfonden; Karolinska Institutet, Stockholm, Sweden, and Örebro University, Örebro, Sweden. Open access funding provided by Uppsala University.

\section{Availability of data and materials}

The data set supporting the conclusion of this article is available on request to the corresponding author.

\section{Ethics approval and consent to participate}

This study was approved by the Ethical Review Board at Uppsala University (Dnr. 2015/094). Patients were contacted by letter and agreed to participate in the study by written informed consent.

\section{Consent for publication}

A written, signed informed consent to publish all data and any accompanying images was obtained from each patient.

\section{Competing interests}

The authors declare that they have no competing interests.

\section{Author details}

${ }^{1}$ Department of Surgical Sciences/Orthopedics \& Hand Surgery, Uppsala University Hospital, Entrence 701 floor, 75185 Uppsala, Sweden. ${ }^{2}$ Department of Orthopedics, Falu Lasarett, Lasarettsvägen 10, 79182 Falun, Sweden. ${ }^{3}$ School of Medical Sciences, Örebro University and University Hospital, Örebro, Sweden. ${ }^{4}$ Division of Pediatric Endocrinology and Center of Molecular Medicine, Department of Women's and Children's Health, Karolinska Institutet and University Hospital, Stockholm, Sweden. ${ }^{5}$ Elisabeth Hospital Aleris, Geijersgatan 20, 75226 Uppsala, Sweden.

Received: 28 March 2020 Accepted: 22 April 2020

Published online: 29 April 2020

\section{References}

1. Buckwalter JA. Were the hunter brothers wrong? Can surgical treatment repair articular cartilage? lowa Orthop J. 1997;17:1-13.

2. Buckwalter JA, Mankin HJ. Articular cartilage: degeneration and osteoarthritis, repair, regeneration, and transplantation. Instr Course Lect. 1998:47:487-504.

3. Skoog T, Ohlsén L, Sohn SA. Perichondrial potential for cartilagenous regeneration. Scand J Plast Reconstr Surg. 1972;6:123-5.

4. Lynch TS, Patel RM, Benedick A, Amin NH, Jones MH, Miniaci A. Systematic review of autogenous osteochondral transplant outcomes. Arthroscopy. 2015;31:746-54.

5. Angele P, Niemeyer P, Steinwachs M, Filardo G, Gomoll AH, Kon E, et al. Chondral and osteochondral operative treatment in early osteoarthritis. Knee Surg Sports Traumatol Arthrosc. 2016;24:1743-52.

6. Campbell AB, Pineda M, Harris JD, Flanigan DC. Return to sport after articular cartilage repair in athletes' knees: a systematic review. Arthroscopy. 2016;32:651-668.e1. 
7. Brittberg $M$, Lindahl A, Nilsson A, Ohlsson C, Isaksson O, Peterson L. Treatment of deep cartilage defects in the knee with autologous chondrocyte transplantation. N Engl J Med. 1994;331:889-95.

8. Peterson L, Vasiliadis HS, Brittberg M, Lindahl A. Autologous chondrocyte implantation: a long-term follow-up. Am J Sports Med. 2010;38:1117-24.

9. Engkvist O, Ohlsén L. Reconstruction of articular cartilage with free autologous perichondrial grafts. An experimental study in rabbits. Scand J Plast Reconstr Surg. 1979;13:269-74.

10. Bairati A, Comazzi M, Gioria M. A comparative study of perichondrial tissue in mammalian cartilages. Tissue Cell. 1996;28:455-68.

11. Duynstee ML, Verwoerd-Verhoef HL, Verwoerd CD, Van Osch GJ. The dual role of perichondrium in cartilage wound healing. Plast Reconstr Surg. 2002; 110:1073-9.

12. Long F, Linsenmayer TF. Regulation of growth region cartilage proliferation and differentiation by perichondrium. Development. 1998;125:1067-73.

13. Koziel L, Wuelling M, Schneider S, Vortkamp A. Gli3 acts as a repressor downstream of Ihh in regulating two distinct steps of chondrocyte differentiation. Development. 2005;132:5249-60.

14. Kronenberg HM. The role of the perichondrium in fetal bone development. Ann N Y Acad Sci. 2007;1116:59-64.

15. Scott-Savage P, Hall BK. Differentiative ability of the tibial periosteum for the embryonic chick. Acta Anat (Basel). 1980;106:129-40.

16. Pathi S, Rutenberg JB, Johnson RL, Vortkamp A. Interaction of Ihh and BMP/ noggin signaling during cartilage differentiation. Dev Biol. 1999;209:239-53.

17. Colnot C, Lu C, Hu D, Helms JA. Distinguishing the contributions of the perichondrium, cartilage, and vascular endothelium to skeletal development. Dev Biol. 2004;269:55-69.

18. Upton J, Sohn SA, Glowacki J. Neocartilage derived from transplanted perichondrium: what is it? Plast Reconstr Surg. 1981;68:166-74.

19. Diaz-Flores L, Rodriguez E, Gayoso MJ, Gutierrez R. Growth of two types of cartilage after implantation of free autogeneic perichondrial grafts. Clin Orthop Relat Res. 1988;234:267-79.

20. Kagimoto S, Takebe T, Kobayashi S, Yabuki Y, Hori A, Hirotomi K, et al. Autotransplantation of monkey ear perichondrium-derived progenitor cells for cartilage reconstruction. Cell Transplant. 2016;25:951-62.

21. Engkvist O, Johansson SH, Ohlsén L, Skoog T. Reconstruction of articular cartilage using autologous perichondrial grafts. A preliminary report. Scand J Plast Reconstr Surg. 1975;9:203-6.

22. Engkvist O, Johansson SH. Perichondrial arthroplasty. A clinical study in twenty-six patients. Scand J Plast Reconstr Surg. 1980;14:71-87.

23. Pastacaldi P. Perichondrial wrist arthroplasty--a follow-up study in 17 rheumatoid patients. Ann Plast Surg. 1982;9:146-51.

24. Seradge H, Kutz JA, Kleinert HE, Lister GD, Wolff TW, Atasoy E. Perichondrial resurfacing arthroplasty in the hand. J Hand Surg. 1984:9:880-6.

25. Katsaros J, Milner R, Marshall NJ. Perichondrial arthroplasty incorporating costal cartilage. J Hand Surg Br. 1995:20:137-42.

26. Vedung $T$, Vinnars B. Resurfacing the distal radioulnar joint with rib perichondrium-a novel method. J Wrist Surg. 2014:3:206-10.

27. Gummesson C, Ward MM, Atroshi I. The shortened disabilities of the arm, shoulder and hand questionnaire (QuickDASH): validity and reliability based on responses within the full-length DASH. BMC Musculoskelet Disord. 2006;7:44.

28. Wilbrand $\mathrm{H}$, Engkvist O. Radiography in joint reconstruction with perichondrial grafts. Acta Radiol Diagn. 1979;20:967-76.

29. Yang G, McGlinn EP, Chung KC. Management of the stiff finger: evidence and outcomes. Clin Plast Surg. 2014;41:501-12

30. Widenfalk B, Engkvist O, Ohlsén L, Segerström K. Perichondrial arthroplasty using fibrin glue and early mobilization. An experimental study. Scand J Plast Reconstr Surg. 1986;20:251-8.

31. Bouwmeester SJ, Beckers JM, Kuijer R, van der Linden AJ, Bulstra SK. Longterm results of rib perichondrial grafts for repair of cartilage defects in the human knee. Int Orthop. 1997;21:313-7.

32. Silverman IW. Age as a moderator of the secular trend for grip strength in Canada and the United States. Ann Hum Biol. 2015;42:199-209.

33. Linscheid RL. Implant arthroplasty of the hand: retrospective and prospective considerations. J Hand Surg Am. 2000;25:796-816.

34. Decker RS, Um H-B, Dyment NA, Cottingham N, Usami Y, EnomotoIwamoto $\mathrm{M}$, et al. Cell origin, volume and arrangement are drivers of articular cartilage formation, morphogenesis and response to injury in mouse limbs. Dev Biol. 2017;426:56-68.
35. Skoog T, Johansson SH. The formation of articular cartilage from free perichondrial grafts. Plast Reconstr Surg. 1976;57:1-6.

36. O'Driscoll SW, Fitzsimmons JS. The role of periosteum in cartilage repair. Clin Orthop Relat Res. 2001;391(Suppl):190-207.

37. Netscher D, Eladoumikdachi F, Gao YH. Resurfacing arthroplasty for metacarpophalangeal joint osteoarthritis: a good option using either perichondrium or extensor retinaculum. Plast Reconstr Surg. 2000;106: 1430-3.

38. Adkinson JM, Chung KC. Advances in small joint arthroplasty of the hand. Plast Reconstr Surg. 2014;134:1260-8.

39. Goldfarb CA, Stern PJ. Metacarpophalangeal joint arthroplasty in rheumatoid arthritis. A long-term assessment. J Bone Joint Surg Am. 2003; 85:1869-78.

40. Chan K, Ayeni O, McKnight L, Ignacy TA, Farrokhyar F, Thoma A. Pyrocarbon versus silicone proximal interphalangeal joint arthroplasty: a systematic review. Plast Reconstr Surg. 2013;131:114-24.

41. Boe C, Wagner E, Rizzo M. Long-term outcomes of silicone metacarpophalangeal arthroplasty: a longitudinal analysis of 325 cases. $J$ Hand Surg Eur. 2018;43:1076-82.

42. Cook SD, Beckenbaugh RD, Redondo J, Popich LS, Klawitter JJ, Linscheid RL. Long-term follow-up of pyrolytic carbon metacarpophalangeal implants. J Bone Joint Surg Am. 1999:81:635-48.

43. Sweets TM, Stern PJ. Pyrolytic carbon resurfacing arthroplasty for osteoarthritis of the proximal interphalangeal joint of the finger. J Bone Joint Surg Am. 2011;93:1417-25.

44. Pritsch T, Rizzo M. Reoperations following proximal interphalangeal joint nonconstrained arthroplasties. J Hand Surg Am. 2011;36:1460-6.

45. Wagner ER, Weston JT, Houdek MT, Luo TD, Moran SL, Rizzo M. Mediumterm outcomes with Pyrocarbon proximal Interphalangeal Arthroplasty: a study of 170 consecutive Arthroplasties. J Hand Surg Am. 2018:43:797-805.

46. Mora AN, Earp BE, Blazar PE. Midterm clinical and radiographic follow-up of pyrolytic carbon PIP arthroplasty. J Hand Surg Am, 2020. 45:253.e1-6.

47. Murray PM, Linscheid RL, Cooney WP, Baker V, Heckman MG. Long-term outcomes of proximal interphalangeal joint surface replacement arthroplasty. J Bone Joint Surg Am. 2012:94:1120-8.

48. Jennings $C D$, Livingstone DP. Surface replacement arthroplasty of the proximal interphalangeal joint using the SR PIP implant: long-term results. J Hand Surg Am. 2015;40:469-73.

49. Frueh FS, Calcagni M, Lindenblatt N. The hemi-hamate autograft arthroplasty in proximal interphalangeal joint reconstruction: a systematic review. J Hand Surg Eur. 2015;40:24-32.

50. Millesi $\mathrm{H}$. Late results of the corium arthroplasty on the finger joints. Handchirurgie. 1969;1:216-22.

51. Hunziker EB. Articular cartilage repair: problems and perspectives. Biorheology. 2000;37:163-4.

52. Buckwalter JA, Mow VC, Ratcliffe A. Restoration of injured or degenerated articular cartilage. J Am Acad Orthop Surg. 1994;2:192-201.

\section{Publisher's Note}

Springer Nature remains neutral with regard to jurisdictional claims in published maps and institutional affiliations.

Ready to submit your research? Choose BMC and benefit from:

- fast, convenient online submission

- thorough peer review by experienced researchers in your field

- rapid publication on acceptance

- support for research data, including large and complex data types

- gold Open Access which fosters wider collaboration and increased citations

- maximum visibility for your research: over $100 \mathrm{M}$ website views per year

At $\mathrm{BMC}$, research is always in progress.

Learn more biomedcentral.com/submission 